\title{
Investigating the Rate of Applying the Ethic's Charter Components and its relation to Power Management Components in Isfahan Educational Departments
}

\author{
Shadi Sadat Hoseini (Corresponding author), \\ MA student of Educational management, Islamic Azad University \\ Khorasgan branch, Iran
}

Seyed Ali Siadat

Professor of University of Isfahan

Isfahan, Iran

Received: August 29, 2015 Accepted: September 29, 2015 Published: March 4, 2016

doi:10.5296/ire.v4i1.9144 URL: http://dx.doi.org/10.5296/ire.v4i1.9144

\begin{abstract}
The purpose of this study was to determine the relationship between legal power and the ethic's charter components applying. This study is a descriptive cross-functional. The population consisted of 1,539 managers, planners and experts in education departments of Isfahan; the 220 out of that were selected as study's sample by Morgan and stratified random sampling with the population size based on their business and position. In the present study, two questionnaires were used for collecting data; power supplies questionnaire and component of ethics charter inventory. The results show that: (1) The component of ethics charter, administrative, environmental and personal-care have no legal relation with using managers, planners and experts from the legal power source. (2) There is a significant relationship between the power source reference and the rate of applying the ethics charter, administrative, environmental, personal and caring components from the managers, planners and experts' point of view. (3) There is a significant relationship between the reward and the application of ethic's charter components sin managers, planners and experts of the departments of Educational systems in Isfahan. (4) The punishment's power source has its effects only on three ethics charter's environmental component in managers, planners and agencies' experts of Isfahan and can remain in the regression equation, while the mentioned power source has no effect on
\end{abstract}


management component and personal-care of managers, planners and experts. (6) There is no meaningful relationship between the level of expertise and the application of ethics' charter component among the managers, planners and experts of Isfahan educational departments. (7) There is no meaningful difference between the power source and the application of ethics' charter component among managers, planners and experts of Isfahan educational departments in terms of the components of the age, sex and position.

Keywords: power sources, ethic's charter component, managers, planners and experts

\section{Introduction}

Education is one of the major organizations of the country and is responsible for many public services. With regards to the importance of the educational system as one of the basic social essentials; it would act more successful and powerful, if the standards of professional ethics prevail there. In fact, staff carrying out their duties more motivated and committed to the ethical principles, with more commitment and responsibility; if the managers provide appropriate levels of power resources, work and optimal performances' principals to facilitate the ethics' charters components. It is clear that the manager would have a very important role in organization's educating and development by applying appropriate or inappropriate policies and procedures in the distribution and power sources' application. In this way, the present study examines the relationship between the ethic's charter components application and its relation with power management components in Isfahan educational system.

First, the concept of professional morality were used as jobs and employment ethic; today, some of the professional ethics' authors use the first concept to define the meaning of it and this is the equivalent for the work ethic and professional ethics in Farsi (Hosseiniyan, 2007-2008).

Term "ethics charter component" with professional ethics meaning is the observer for our social and organizational behavior. Professional ethic is beyond the personal and professional ethics; although it covers both. By nature, professional ethics is not the matter of individual responsibility for their own and professional behavior as human being but is discussing the institution and organizational responsibility as a legal unit against all indoor and outdoor environmental elements (Hosseiniyan, 2007-2008). Ferasat khah expresses that "the ethic charter component proceeds the ethical issues and questions and a professional arrangement's principles and values (Shekar Khah, 2007-2008; quoted Golmohammadi et al., 2011-2012). In most definitions of professional ethics there are two features (1) individual's nobility, and individualism; (2) the limitation of liability and ethical requirements of the job. According to this view, management ethics has been brought forth to discussion recently inhuman resources management (Gharamaleki, 2010-2011). The ethics components were used in its initial conceptualization with the meaning of professional ethics and business ethics (Falletta, 2008). At the beginning of the third millennium, the diversity of tools used in the life process and rapid change are increasing every day. Developments and changes are evident in all life facets. "Ethic's charter components' application is inevitable and is being designed and managed for making organizations safety. Organizations should make changes in order to accommodate the environment demands (Bennebroek Gravenhorst, 2003). 
Although it is possible to find records about the traditional sense of professional ethics in the fields of medicine and politics in our nation's history, but undoubtedly the literal term "professional ethics" can be seen in some modern concepts and writing and it seems that it is a translation of its foreign term (Folger \& Skarlicki 2001). Some efforts have been conducted for compiling the ethic's charter components and standards (Khosraviyan, 2006-2007).

Robbins (1996-1997) defines the power as: "the potential power of "A" to make effect on the behavior of "B" in a way that forces "B" to do something (if it were otherwise, he would not) "(p. 291).

Every source of the power may exist in all levels of an organization. These sources include: legal authority, reference power, reward power, punishment power and expertise power. In the information age, any organization or company that uses power supplies appropriately would be distinct and superior to its competitors. Gathering the right information at the right time is the basis of organizations' motion (Choo, 2007). Other benefits of the proper power supplies' application power the following could be mentioned: - Evaluating the total ability of the organizational system, -Understanding the dependencies' patterns, -Identifying institutional-organizational strengths and weaknesses and creating a space for communication improvement between subsystems, -Improving subsystems in the way of changing and innovating, -Creating commitment for trying organizational changes, strong leadership and greater profitability (Albrecht, 2003).

Today, the ethic's charter components' components are defined as moral responsibilities of enterprises and organizations which are more comprehensive than the traditional definition. In this view, the organization is a legal entity with two types of responsibilities: 1-The legal-criminal responsibility, and 2- Ethical responsibilities. Generally, the personal and interpersonal ethics have been emphasized in the new ethics' approaches. Among them moral duties towards the audience and community organizations are notable (Cable, 2008).

Due to the fact that education is one of the most important organizations and the importance of the application of professional ethics, managers should emphasize the application component components of conduct by its employees and for this purpose they should use various sources of their power (French \& Bell, 2007-2008, p. 308). Therefore, it can be concluded that the ethics conceptual is extensive, complete and precious. Applying ethic's charter components is involving important issues. If an organization wants to be healthy, it should attempt to comply with all or most of the positive moral points (Zredenek \& Schochor, 2007).

Beig Zaad and colleagues (2011-2012; quoted Nemati \& Mohseni, 2011-2012), Sharifi and Elahi Nezhad (2012-2013; quoted Araste and Jahed, 2012-2013), Hosseini 2012-2013; quoted Araste and Jahed, 2012-2013),Imani Pour (2013-2014; quoted Dehghani et al., 2013-2014), Rucinski and Bauch (2006), Langlois and Lapointe (2007), and Zdenek and Schochor(2007), have focused on professional ethics in their researches.

Cable (2008) conducted a study on the relationship between employee resistances against management influence in organizational change. Research has shown that the staff's resistance presented penetrating management and the strength of leader-follower, both, which was being 
used by the managers. The present study investigates the ethics components' application and its relationship with the power sources of Isfahan education system.

\section{Research Hypotheses}

There is a relationship between ethics components' application and power sources, legal authority, reference, reward, punishment and expertise power among managers, planners and experts of the educational department in Isfahan.

\section{Research Methodology}

According to the fact that in this study, researcher attempts to "determine the relationship between the ethic's charter components application and its relation with the management's power sources in education department of Isfahan"; the methodology is descriptive and correlational. The present study is cross- correlational with regards to the subject and its purposes. The study's statistical population includes all managers, planners and experts in education departments in Isfahan in 2014-2015; with the total number of 1593 individual which were specified by gender, work experience and educational grade includes individuals who are working in various sectors of education department in Isfahan.

Since, the variance was statistically undefined in the present study; conducting a pilot study on a group of people in order to determine the variance was needed. To this end, a group of 40 managers, planners and experts in education departments of Isfahan were selected randomly, then the ethics components' questionnaire were distributed among them; after extracting the data for each group, the 220 people sample size has obtained by using Morgan model; but in the end 200 questionnaires were answered. Using stratified random sampling olume, 220 were selected as sample.

In the present study, two questionnaires were used to collect data:

1. Power components of ethics charter inventory. 2. Inventory of Manager Power Sources.

The researcher made questionnaire containing 30 questions with a range of five alternatives which were assessing the power sources. The questionnaire was given to some specialists, professors, supervisors and advisors to approve the validity of the questionnaire. To assess reliability, after conducting a pilot study and determining the variance of the questions, the Cronbach's alpha coefficient was calculated and the 0.87 ratio was achieved (Sharif $\&$ Sharifi, 2002). The obtained reliability coefficients of questionnaire component (legal, professional, reward, coercive, reference) are $0.84,0.87,0.71,0.90$ and 0.0 respectively.

The Dehghani et al.'s (2013-2014) questionnaire of ethic's charter components is used in this survey. This questionnaire investigated the ethics charter components in three management, environment and personal dimensions. The data was analyzed with the calculation of relative frequency of the answers and weight frequency between domains. In order to collect data a questionnaire was prepared that was consisted of three field of administrative, environmental and personal-care. The ethics components' investigation part included 33 questions (management domain, 14 questions, 5 questions related to the environment, and individual care domain 14 questions). Items have been answered by the five degree scale. Investigating 
the validity of the tool's content has performed and reformed by supervisors, consultants and 10 masters of the training science, psychology and management. Determining the reliability and the internal stability, the questionnaire completed and the Cronbach's Alpha coefficient 0.89 were obtained. The reliability coefficients obtained by questionnaire component (management, environmental, personal-care) are $0.86,0.87$ and 0.89 respectively.

\section{The Findings}

First research hypothesis: There is a relationship between ethics components' application and legal authority, among managers, planners and experts of the educational department in Isfahan.

Table 1. Results of regression coefficients of net and gross weights of the ethics components legal authority

\begin{tabular}{ccccc}
\hline Source & SE & Regression & T Value & Significance level \\
\hline Management & $0 / 14$ & $0 / 19$ & $1 / 55$ & $0 / 12$ \\
Environmental & $0 / 08$ & $0 / 19$ & $1 / 62$ & $0 / 11$ \\
Individual care & $0 / 16$ & $0 / 14$ & $1 / 07$ & $0 / 29$ \\
\hline
\end{tabular}

Regression analyzes on $\alpha=0.05$ levels indicates that legal authority source has no effect on any of the components of ethics charter among managers, planners and experts' perspective of education department in Isfahan. In other words, the components of the ethics, management, environmental and personal-care charter have no relation with the managers, planners and experts' legal authority source application. Therefore the legal authority source is not associated with any of the ethic's charter components.

Second research hypothesis: There is a relationship between ethics components' application and reference power, among managers, planners and experts of the educational department in Isfahan.

Table 2. Results of the regression coefficients, net and gross weights of the reference power source on the application of ethic's charter components

\begin{tabular}{cccccc}
\hline Source & SE & Regression & T Value & Coefficient of determination & Significance level \\
\hline Management & $0 / 09$ & $0 / 28$ & $2 / 76$ & $0 / 29$ & $0 / 007$ \\
Environmental & $0 / 10$ & $-0 / 26$ & $2 / 39$ & $0 / 29$ & $0 / 02$ \\
Personal-Care & $0 / 09$ & $-0 / 31$ & $2 / 37$ & $0 / 29$ & $0 / 02$ \\
\hline
\end{tabular}

According to the results, a reference power source has effects on management, environmental and personal-care components of managers, planners and experts' ethic charter in education 
departments in Isfahan and can remain in the regression equation; therefore the amount of ethic charter's application by managers, planners and experts can be influenced and changed by the reference power source. The determination coefficient indicates that 0.29 of the obtained scores in the mentioned components out of ethic's charter components among managers, planners and experts in Isfahan has been affected by reference power source.

Third research hypothesis: There is a relationship between ethics components' application and reward power source among managers, planners and experts of the educational department in Isfahan.

Table 3. The results of regression coefficient of net and gross weights of reward power source on the application of ethic's charter components

\begin{tabular}{cccccc}
\hline Source & SE & Regression & T Value & Coefficient of determination & Significance level \\
\hline Management & $0 / 09$ & $0 / 42$ & $3 / 26$ & $0 / 17$ & $0 / 001$ \\
Environmental & $0 / 09$ & $0 / 35$ & $2 / 36$ & $0 / 17$ & $0 / 02$ \\
Personal-Care & $0 / 09$ & $-0 / 34$ & $2 / 36$ & $0 / 17$ & $0 / 02$ \\
\hline
\end{tabular}

Regression analyzes in $\alpha=0.05$ levels show that reward power source is effective on management, environmental and personal-care components among managers, planners and experts and can remain in the regression equation; therefore the components of ethics can be influenced and changed by the reward power source. The determination coefficient indicates that that 0.17 of the obtained scores in the mentioned components out of ethic's charter components among managers, planners and experts in Isfahan has been affected by reward power source. So reward power source has a positive significant correlation with management, environmental and personal-care components.

The fourth research hypothesis: There is a relationship between ethics components' application and punishment power source among managers, planners and experts of the educational department in Isfahan.

Table 4. The results of regression coefficient of net and gross weights of punishment power source on the application of ethic's charter components

\begin{tabular}{llrrrr}
\hline Source & SE & Regression & T Value & Coefficient of determination & Significance level \\
\hline Management & $0 / 17$ & $0 / 06$ & $0 / 37$ & $0 / 08$ & $0 / 71$ \\
Environmental & $0 / 19$ & $-0 / 17$ & $2 / 04$ & $0 / 12$ & $0 / 04$ \\
Personal-Care & $0 / 09$ & $0 / 11$ & $0 / 75$ & $0 / 08$ & $0 / 45$ \\
\hline
\end{tabular}

Regression analyzes in $\alpha=0.05$ levels show that punishment power source is effective only on 
environmental components among managers, planners and experts and can remain in the regression equation; while the mentioned power source has no effect on management and personal-care components and must be removed from the equation. Thus, among the ethic's charter components, the environmental component is the one which is affected by punishment power source and can be changed. The determination coefficient indicates that that 0.12 of the obtained scores in the mentioned components has been affected by punishment power source. So punishment power source has a negative significant correlation with ethic's charter components.

Fifth research hypothesis: There is a relationship between ethics components' application and expertise power among managers, planners and experts of the educational department in Isfahan.

Table 5. The net and gross weight regression coefficient on the application of specialized power supply components of Ethics

\begin{tabular}{ccccc}
\hline Source & SE & Regression & T Value & Significance level \\
\hline Management & $0 / 20$ & $0 / 043$ & $0 / 35$ & $0 / 72$ \\
Environmental & $0 / 11$ & $0 / 11$ & $0 / 98$ & $0 / 33$ \\
Personal-Care & $0 / 24$ & $0 / 03$ & $0 / 20$ & $0 / 84$ \\
\hline
\end{tabular}

Regression analyzes in $\alpha=0.05$ levels indicates that expertise power source has no effect on any ethic's charter components among managers, planners and experts. In other words, the ethic's charter components; management, environmental and personal-care; are not impressed by managers, planners and experts' using of expertise power source.

\section{Discussion and Conclusion}

The first hypothesis' results show that legal power source has no effect on any ethic's charter components from Isfahan education department's managers, planners and experts' perspective. In other words, the components of ethics, management, environmental and personal-care have no relation with managers, planners and experts' using the legal power source. The legal power source is not associated with any of the ethic's charter components.

The obtained results are consistent with Puriyan (2008-2009), Taheri (2000-2001), Hadiyan. (2001-2002), Nokhod Saz (2009-2010; quoted Nemati and Mohseni, 2011-2012), Krishnan (2003), and Langlois \& Lapointe's (2007) findings. These findings can be explained so that there is no relation between using the legal power tools and its necessities and the professional ethic's charter components application in Isfahan education department. Indeed, if the organization's applicatory power nature and the individual's relationship are being legal and the powers and responsibilities' basis for individuals are determining by preset legal licensing, standards and guidelines; it has no effect on the reception and the use of ethic's charter components in management, environmental and personal dimensions. According to the second 
hypothesis' results, the reference power source has effects on management, environmental and personal-care of ethic charter of managers, planners and experts in education departments and can remain in the regression equation. Therefore the amount of ethic charter's application by managers, planners and experts can be influenced and changed by the reference power source. The determination coefficient indicates that 0.29 of the obtained scores in the mentioned components out of ethic's charter components among managers, planners and experts in Isfahan has been affected by reference power source.

The obtained results are consistent with Puriyan (2008-2009), Taheri (2000-2001), Hadiyan. (2001-2002), Nokhod Saz (2009-2010; quoted Nemati and Mohseni, 2011-2012), Krishnan (2003), and Langlois\& Lapointe's(2007) findings. Reference power source has a significant effect on management environmental, personal and care of ethic's charter components ,so that by increasing or decreasing the managers' employing the reference power source; the ethic's charter components application would increase or decrease as well; in fact whatever the experts, planners and managers have more responsibilities based on their organizational position and credibility, we could observe increased ethic's charter components application in personal (interpersonal and intrapersonal relationship), environmental (education relationship with clients) and management ( internal affairs).

The third hypothesis' results show that reward power source has effects on management, environmental and personal care components by managers, planners and experts, so ethic's charter components can be influenced and changed .So reward power supply has significant positive correlation with management, environmental and personal care components. The obtained results are consistent with Puriyan (2008-2009), Taheri (2000-2001), Hadiyan. (2001-2002), Nokhod Saz (2009-2010; quoted Nemati and Mohseni, 2011-2012), Krishnan (2003), and Langlois\& Lapointe's(2007) findings. Using reward power tools and encouraging the staffs material and spiritual incentives for managers, planners and experts performance has the same effect on ethic charter components as well as professional ethic application and makes the work space more positive, succulent and lively. These effects are very important in training organizations.

The forth hypothesis' results show that punishment power source has effect only on the environmental component of ethic charter in managers, planners and experts in Isfahan departments while it has no effect on management and personal-care components. Thus, from the managers, planners and experts' point of view; the environmental component is the only component that can be influenced by punishment power source and can be changed. So this power source has a significant negative correlation with ethic charters' environmental component. The research results are aligned with (Beig Zad et al., 2011, 2012, quoted by Nemati and Mihseni, 2011-2012), (Sharifi \& Elahi Nezhad, 2012, 2013; quoted by Araste and Jahed, 2012, 2013), Vimalaseiry (2001), Krishnan (2003), Rosinsky and Bach's (2006) findings.

These findings can be explained as a source negative effect of punishment power on employees' participation within the organization. Using the punishment power source by managers would decrease the employees' participation in education department. In particular 
cases, the use of punishment power will increase ethics in the organization that is essential and needful and in many cases, using this power by the manager was not positive and lowered the efficiency of the organization. In addition, the punishment source on the environmental ethic dimension can be caused by external forces to individuals' performance and possessed temporary performance and did not create commitment and internal motivation for people and would decrease the organizational efficiency and effectiveness in long term.

The fifth hypothesis' results show that specialized power supply of managers, planners and experts about the application of ethics does not affect any of the ethic charter's components. In other words, the components of the ethic charter; means management, environmental and personal care; are not influenced by managers, planners and experts' application of specialized power supply. The results are not aligned with Bach Man, Bowers and Marcus (1998). The reason for this difference could be due to geographic location dis-alignment, folklore, organizational conditions and differences in people's beliefs of that statistical community. The results are consistent with Sanjabi (2000-2001), Hadiyan (2001-2002) and Nour Bakhsh and Mohammadi's (2005-2006) findings. The results can be explained as the use of specialized power source by managers, planners and experts of the education department can not affect the ethic charter components (management, environmental and personal- care) and cannot cause its increase or decrease. However, further research and analysis may require having a definitive statement on this issue, but generally it can be concluded that people specialty is independence from ethic charter components. Giving people responsibilities based on their proficiency, we could not reach ethic's charter components' increasing. In this regard, following statements are suggested; the application of other methods in addition to the legal power source in management system, justifying staffs about the use of reference power source, paying attention to the reward power source for further cooperation, and holding workshops on ethical components.

\section{References}

Albrecht, K. (2002). Organizational intelligence and Knowledge management: Thinking outside the silos. (p. 3). Retrieved from http://www.KarlAlbrecht.com

Albrecht, K. (2008). Knowledge management, organizational intelligence, learning and Complexity. Unesco. Encyclopedia of Life Support Systems (Eolss). Research project. (pp. 5-6). Retrieved from http://www.utdallas.edu

Araste, H. R., \& Jahed, H. (2013). Observance of ethics In the Universities and Higher Educational Center: Choices for Behaviors' Recovery. Journal of Neshat-e-Elm, first period No.2, 40-31.

Bachman, I. G., Bowers, D. G., \& Marcus, P. M (2001). Relationships among organizational health empowerment and principal effectiveness. Columbia: University of Missouri Columbia press.

Bennebroek Gravenhorst, Kilian. M. (2003). "A Different view on Resistance to Change". Power Dynamics and organizational change IV: symposium at the 17th EAwop Conference in Portugal. 
Cable, D. M. (2008). Employee resistance to organizational change: Managerial Influence tactics and leader member exchange. Journal of Applied Psychology, 95(2).

Choo, C. W. (the 2007th). Information management with the organizational intelligence. The art of scanning the environment. ASIS Monograph Series (P. 56). Information Today, Inc: Medford.

Cummings, Thomas. Jay and Orly, Christopher. J. (2007). Organizations' Development (translation Siruos Bararpour). Tehran: Fraz Andysh-e- Sabz Press Institute.

Dehghani, Ali, Dast Paak, Mehdi; Gharib, Alireza (2014). Barriers for Standards' Compliance of Professional Ethics In Clinical Care in Nurses' Perspective. Iranian Journal Education in Medicine Science, 13(5), 430-421.

Falletta, S. (2008). Power resources survey. Training \& Development, 35(40), 2-3.

Folger, R., \& Skarlicki, D. (2001). Unfairness and resistance to change: hardship as mistreatment, Journal of Organizational Change Management, 5(12), 112-120.

French, V., \& Bell, S. H. (2007). Change management in organizations. (Translated by Seyed Mehdi Alvani and Hassan Danaee Fard). Tehran: Safar Publication- Eshraghi.

Gharamaleki, A. F. (2011). Professional ethics. Tehran. SaramadPublishing.

Giangerco, Antonio. (2002). A Review of the literature and a discussion of six issues in the analysis of resistance to change, Liuc papers (n. 79), serie Economia aziendale 7.

Gol Mohammadi, Reza; Motahari Pour, Mohammad; Cheraghi, Moien; Mir Esmaieli, Esmaielof (2012). Essentials of ethic inuniversity education. Hamedan: Publications University.Hamedan Sciences Medical, 2011-2012 (pp. 55-51).

Hadian, M. (2001). An evaluation of the effectiveness of power management and its relationship with Tabas teachers' perspective in 2001 of 2002. MS Thesis, Training Management, Tehran University.

Hosainiyan, S. (2008). Ethics in Counseling and Psychology. Tehran. Kamal Tarbiyat.

Khosraviyan, H. (2007). Examine the relationship between leadership styles and their tendency to change from the Isfahan high schools' teachers. MS Thesis, Department of Education, University of Isfahan.

Krishnan, V. R. (2003). Power and moral leadership: Role of self- other agreement. Leadership Organization Development Journal, 345-351. http://dx.doi.org/10.1108/01437730310494310

Langlois, L., \& Lapointe, C. (2007). Ethical leadership in Canadian school organizations. London. Educational Managers Administration \& Leadership, 35(2), 247. http://dx.doi.org/10.1177/1741143207075391

Nemati Ma, Mohseni. (2011-2012). Ethics inHigher Education: Components, Requirements and Strategies. Tehran: Pazhoheshkade Publication of Strategic Research (pp. 14-16, 28-26). 
Nemati, Ma, Mohsenie. (2010). Morality in Higher Education: Components, Requirements, and Strategies. Tehran: Pazhoheshkade Publication of Strategic Research (pp.14-16).

Nokhod Saz, Mohammad Javad. (2009). Evaluation of the application of professional ethics component in teacher training institutions of Yazd and Isfahan., Master MS Thesis, Training Department, Isfahan University.

Nour Bakhsh, M., and Mohammadi, S. (2005). Investigating the relationship between managers' leadership styles and power sources in physical-education college from the perspective of faculty members. Harkat Journal, 19, 124-109.

Puriyan, Khodayar. (1999). The relationship between the power types used by principals and organizational climate in schools. MS Thesis, Department of Education, University of Al-Zahra.

Rucinski, D. A, \& Bauch, P. A. (2006). Reflective, ethical and moral constructs in educational leadership preparation: Effects on graduates practices. Journal of Educational Adminisreartin, 44(5), 487-508.

Sanjabi, S. (2000). Evaluation of the relationship between power sources and stress among teachers in public girls' high schools in Tehran, 2001-2002. MS Thesis, Educational Management, Shahid Beheshti University.

Sarmad, Zohreand colleagues. (2006-2007). Methods of Research in the Behavioral Sciences. Tehran: Agaah Publication (pp. 115-111).

Sharifi, H. P., \& Sharifi, N. (2002). Methods of Research in Behavioral Sciences. Tehran: Sokhan Publication.

Taheri, S. (2000). Evaluation of the relationship between power sources used by managers and organizational climate in male high school in Tehran. MS Thesis, Shahid Beheshti University.

Torabiyan, S.. (2009). Evaluation of the relationship between power sources used by managers and organizational climate in Kerman female highschool teachers' perspective. MS Thesis, Department of Education, Payam Noor University.

Wimalasiri, J. S. (2001). Moral reasoning capacity of management students and practitioners: An Empirical study in Australia. Journal of Managerial Psychology, 66(8), 614-634. http://dx.doi.org/10.1108/EUM0000000006303

Zdenek, B., \& Schochor, D. (2007). Developing moral literacy in classroom. Journal of Educational Administration, 45(4), 514-532. http://dx.doi.org/10.1108/09578230710762481

\section{Copyright Disclaimer}

Copyright reserved by the authors.

This article is an open-access article distributed under the terms and conditions of the Creative Commons Attribution license (http://creativecommons.org/licenses/by/3.0/). 